\title{
Inguinal Hernias Repair by Laparascopy (TEP)
}

\section{Olga Caridad León González ${ }^{1}$, Pedro Rolando López Rodríguez ${ }^{2 *}$, Lais Angélica Ceruto Ortiz ${ }^{3}$, Jorge Agustín Satorre Rocha ${ }^{4}$ Eduardo García Castillo ${ }^{5}$ and Luis Marrero Quiala ${ }^{6}$}

1I Degree Specialist in General Surgery, Assistant Professor and Assistant Researcher, Cuba

${ }^{2}$ II Degree Specialist in General Surgery, Consulting Professor, Assistant Professor and Assistant Researcher, Cuba

${ }^{3}$ Resident of 3rd Year in General Surgery, Instructor Teacher, Cuba

${ }^{4}$ First Degree Specialist in General Surgery, Assistant Professor, Cuba

${ }^{5}$ First Degree Specialist in General Surgery, Assistant Teacher, Cuba

${ }^{6}$ First Degree Specialist in General Surgery, Assistant Professor, Cuba

*Corresponding author: Pedro Rolando López Rodríguez, National Hospital, Calle Continental No. 152 between Calle D'Strampes and Calle Goicuría, Sevillano, October 10, Havana, Cuba; Tel: +5376413062; E-mail: lopezp@infomed.sld.cu, pedro.rolando.lopez42@gmail.com

Received: December 04, 2021; Accepted: December 14, 2021; Published: December 29, 2021

\begin{abstract}
Introduction: The hernia affection is one of the processes that has been studied into much detail and whose treatment pursues excellence, although many controversies are still yet to be resolved. Laparoscopy repair of inguinal hernia is a treatment method that improves the quality of management given to our patients.
\end{abstract}

Objective: To identify perioperative events, surgical complications and to evaluate the pain referred for the patients who have had inguinal hernia repair by the laparoscopic method (TEP).

Methods: A prospective and descriptive study was done on 80 patients who have had endoscopic (TEP) repair of inguinal hernias between January 2013 and December 2020.

Results: We performed 100 hernioplastias by laparocoscopy in 80 patients. The male sex predominated in a 5:1 ratio and the surgical time average was, 53.5 minutes for unilateral hernias and 71.3 minutes for the bilateral ones. The most frequent complication in the transoperatory stage was "minor bleeding". At 15 days after surgery, $86.3 \%$ of the operated did not complain of pain, but social and laboral reintegration was at a $34 \%$ of the total.

Conclusions: Laparoscopic inguinal hernioplasty is a good therapeutic option, mainly in patients with bilateral and reproduced inguinal hernias.

Keywords: Hernia recurrence, Inguinal hernia, Laparoscopic hernioplasty

\section{Introduction}

Since the concept of endoscopic inguinal hernia repair was first described by Ger in 1982, endoscopic techniques have been modified; It was a time when failures and complications - coupled with high cost - outweighed initial enthusiasm [1]. Laparoscopic hernioplasty (LH) has gained popularity in the last decade and numerous controlled studies appear in the literature comparing laparoscopic techniques with conventional ones. [2] In recent years, HL, despite being one of the most controversial laparoscopic procedures, has established itself as a therapeutic option to consider. The advantages of this method are demonstrated in bilateral, recurrent hernias and in the labor-active subject, who requires early return to work [3].

\section{Method}

Between January 2013 and December 2020, a prospective, descriptive, longitudinal-cut study was carried out in 80 patients operated on by endoscopy (PET) with the diagnosis of inguinal hernia, at the General Teaching Hospital "Enrique Cabrera". All patients who agreed with the type of surgical intervention, the study and who gave their informed consent were included; patients older than 30 years classified ASA I-III, without anesthetic contraindications for laparoscopic intervention and patients classified as Nyhus III and IV. Patients with previous surgical wounds in the inguinal region, to operate, not dependent on reproduced inguinal hernias and patients with complicated, irreducible or slipped inguinal hernias; they were excluded. The surgical techniques were: totally extraperitoneal laparoscopic inguinal hernioplasty (TEP). The PET technique was performed with some variants such as: no use of the balloon trocar, the preperitoneal space was decolorized by means of the $0^{\circ}$ laparoscope and the insufflation of $\mathrm{CO} 2$ at $13 \mathrm{mmHg}$. In patients with large hernial rings, a polypropylene cone was placed in the hernial defect and subsequently a $15 \times 12 \mathrm{~cm}$ polypropylene prosthesis. There was no need to fasten the meshes with clips [4]. In the immediate postoperative period, the visual pain scale analog scale (VAS) was applied and a pain value was assigned by means of "little faces", which starts from very happy (I value) to very sad (X value). Pain quantification was repeated in consultation 7 days, 15 days and one month after the operation. 


\section{Results}

100 hernias were operated on in 80 patients (20 patients [25\%] had bilateral hernias, 85 primary hernias, and 15 reproduced hernias). The average age was 55.6 years, the youngest patient was 30 years old and the oldest was 77 years old, but the majority (14 patients) belonged to the fifth decade of life. The male sex predominated in $84 \%$, which represented a male/female ratio of $5: 1.43 \%$ of the patients made great physical efforts on a regular basis.

Table 1 shows that 36 patients had the habit of smoking, which represents $45 \%$ of the total and 17 consumed alcohol for $21.2 \%$.

Table 2 shows that right hernias were more frequent in $54.0 \%$ of the total; the indirect variety with great dilation of the annulus and destruction of the posterior wall (IIIb) was the most frequent (41 hernias). Nine femoral hernias and 15 recurrent hernias were operated on.

The 100 surgeries were performed by PET technique (100.0\%). Two of the patients in whom a PET technique was started had to be converted to a conventional prosthetic technique due to accidental perforation of the peritoneum, passing $\mathrm{CO} 2$ into the peritoneal cavity, and consequently, the loss of the preperitoneal surgical space, and another was the conversion of a failed PET technique.

The mean surgical time for unilateral hernias was $53.5 \mathrm{~min}$, with a minimum time of $25 \mathrm{~min}$ and a maximum of $120 \mathrm{~min}$. In bilateral repairs, the average surgical time was $71.3 \mathrm{~min}$, with a minimum of 40 min and a maximum of 110 minutes. The hospital stay was less than 24 hours in 70 patients $(87.5 \%)$, in 5 patients it extended from 24 to 48 hours and in 5 patients it lasted more than 48 hours.

Table 3 shows minor bleeding as the most frequent complication in the intraoperative period, in 22 repairs $(22.0 \%)$ that originated 13

Table 1: Toxic habits and personal pathological history (APP).

\begin{tabular}{|l|c|c|}
\hline Toxic habits and (APP) & Frequency & \% \\
\hline Chronic Cough & 6 & 7,5 \\
\hline COPD & 4 & 5,0 \\
\hline Constipation & 7 & 8,7 \\
\hline Heart disease & 7 & 8,7 \\
\hline Diabetes Mellitus & 7 & 8,7 \\
\hline Smoking & 36 & 45,0 \\
\hline Alcohol consumption & 17 & 21,2 \\
\hline
\end{tabular}

$\mathrm{N}=80$ COPD: Chronic obstructive pulmonary disease.

Tabla 2: Distributión according classificatión to the Nyhus [5].

\begin{tabular}{|c|c|c|c|c|c|}
\hline \multirow{2}{*}{ Classifica-tión } & \multicolumn{2}{|c|}{ Right } & \multicolumn{2}{|c|}{ Left } & \multirow{2}{*}{ Total } \\
\hline & Frequency & $\%$ & Frequency & $\%$ & \\
\hline IIIa & 19 & 33,1 & 16 & 34,7 & $35(35,0 \%)$ \\
\hline IIIb & 21 & 37,8 & 20 & 50,0 & $41(41,0 \%)$ \\
\hline IIIc & 6 & 14,1 & 3 & 10,8 & $9(9,0 \%)$ \\
\hline IV & 8 & 14,8 & 7 & 13,0 & $15(15,0 \%)$ \\
\hline Total & 54 & 54,0 & 46 & 46,0 & $100(100 \%)$ \\
\hline
\end{tabular}

The total is 100 hernias operated on in 80 patients.
Tabla 3: Complications.

\begin{tabular}{|l|c|c|c|}
\hline Complications & $\begin{array}{c}\text { Intraoperative } \\
\text { complications }\end{array}$ & 2 weeks & After 1 month \\
\hline Minor bleeding & $22(22 \%)$ & & \\
\hline Accidental opening of the peritoneum & $9(9,0 \%)$ & & \\
\hline Hematomas & & $13(13,0 \%)$ & \\
\hline Seromas & & $4(4,0 \%)$ & \\
\hline Recurrences & & & $2(2,0 \%)$ \\
\hline
\end{tabular}

Tabla 4: Evaluatión of the Visual Analog Scale (VAS) [6].

\begin{tabular}{|l|c|c|c|c|c|}
\hline VAS & Inmediate preoperative & First day & First week & 15 Days & First month \\
\hline Vas I & $75(93,7 \%)$ & $19(23,7 \%)$ & $52(65,0 \%)$ & $69(86,3 \%)$ & $73(91,3 \%)$ \\
\hline VAS II & $54(6,3 \%)$ & $50(62,5 \%)$ & $15(18,7 \%)$ & $11(13,7 \%)$ & - \\
\hline VAS III & - & $7(8,7 \%)$ & $5(6,3 \%)$ & - & - \\
\hline VAS IV & - & $4(5,1 \%)$ & $4(5,0 \%)$ & - & $7(8,7 \%)$ \\
\hline VAS V & - & - & $4(5,0 \%)$ & - & - \\
\hline
\end{tabular}

hematomas (13.0\%). No complications were observed after the second week, but two patients suffered recurrences $(2.0 \%)$ more than two months after the operation.

Table 4 shows the pain classification according to the VAS scale. In the immediate postoperative period, after the patient recovered from anesthesia, 75 individuals (93.7\%) were classified as VAS I and 5 patients as VAS II. At $24 \mathrm{~h}$ after the operation, 19 patients (23.7\%) were classified as VAS I, 50 (62.5\%) as VAS II, 7 patients as VAS III, and 4 as VAS IV. In the first week postoperative consultation, 52 patients (65.0\%) were classified as VAS I and 15 as VAS II, and two patients with moderate pain (VAS V) appeared in this period. At 15 days after surgery, 69 patients (86.3\%) were VAS I and at one month 73 (91.3\%) were. The incorporation to the usual activities, including work, was of 3 patients (3.7\%) a week after the operation, after 15 days there were 23 patients $(28.7 \%)$ and at month 54 patients, for $67,5 \%$ of the total.

\section{Discussion}

Currently, with the improvement of laparoscopic techniques, inguinal hernia surgery is emerging as safe, feasible and as a good therapeutic option, regardless of the age of the patient; However, the preoperative evaluation of the individual must be correct and thorough, specifically the cardiorespiratory function, since with the TEP method a working space is created between the sheets of the transverse lamina, richly vascularized, so that the absorption and elimination of the $\mathrm{CO} 2$ is greater than that produced in the peritoneal cavity during pneumoperitoneum [5-7].

Although men predominated, there was a slight increase in women in the series with respect to other authors [8] In laparoscopic practice, the finding of hernial defects diagnosed during the intraoperative period is frequent, in men and women, the latter essentially with a history gynecological disorders.

Although the usefulness of hernia repairs in asymptomatic patients is questioned in some articles, the authors consider that it would be beneficial for the patient, if conditions permit, to repair the hernial defect by the TAPP method [9]. 
The relationship between hernial disease and physical exertion has been classic since Cooper's time. In the series, $68 \%$ of the patients performed physical activities that involved great and medium efforts and also analyzing the multifactorial nature in the pathogenesis of hernia disease, it is striking that approximately half of the operated patients were smokers, a factor that influences in collagen metabolism, significantly linked to hernia recurrences [10].

Most of the repairs were by means of the TEP technique and we consider, like other authors, that although the TAPP technique brings us closer to the area from a perspective familiar to the surgeon (peritoneal cavity) and facilitates the so-called "learning curve"; Hernia disease - because it is considered a parietal defect- should be given a solution from this same plane, to avoid the probability of serious complications of the intra-abdominal organs and to leave the transperitoneal method as a tactical resource when the totally extraperitoneal method is unsuccessful [11].

Average surgical time was similar to other series [12]. It is known that this tends to decrease when the surgical team gains in experience. The longest operating time recorded was in a patient, who started with a PET technique, but due to technical difficulties, he was converted to a conventional posterior repair.

The main complications were related to minor intraoperative bleeding and postoperative hematomas. In 3 patients it was necessary to drain the hematoma due to the discomfort caused, however, in the rest of the patients with hematomas and seromas they were treated with conservative measures. In two patients, recurrence occurred 2 months after the operation, which was interpreted as a technical error $[13,14]$.

Our results coincide with numerous studies that affirm less postoperative pain with the use of minimal access techniques, as well as a prompt socio-occupational reincorporation of patients $[1,3,9,15]$ Despite the fact that $70 \%$ and $93.3 \%$ of the patients at 1 week and 15 days after surgery, respectively, had no pain or minimal discomfort; only 18 individuals (30\%) started their usual activities before 15 days. These results contrast with other studies that report a return to work and social activities between 10-15 days postoperatively, although it is likely that some sociocultural factors are influencing these results $[1,16]$.

In the series there were no major intraoperative or postoperative complications, only minor bleeding and bruising. In most of the patients, before 2 weeks postoperatively, the pain disappeared, however, the return to social work activities after 15 days was low.

\section{Conclusions}

Laparoscopic inguinal hernioplasty was an effective therapeutic option, especially for patients with bilateral and reproduced hernias. It provided benefits to patients and families, the former joining work and social activities early.

\section{Conflicts of Interest}

The authors do not declare any conflicts of interest.

\section{References}

1. Ruiz-Funes Map, Farell Rj, Marmolejo Ca, Sosa Laj, Cruz Za (2020) Abordaje De Hernias Poco Frecuentes Por Cirugía De Mínimo Acceso: Serie De Casos. Rev Mex Cir Endoscop 21: 6-14.

2. Magnus H, Anders B, Westerdahl J (2008) Laparoscopic Extraperitoneal Inguinal Hernia Repair Versus Open Mesh Repair: Long-Term Follow-Up Of A Randomized Controlled Trial. Surgery 143: 313-317. [crossref]

3. Bittner R, Bain K, Bansal Vk, Berrevoet F, Bingener-Casey J, et al. (2019) Update Of Guidelines For Laparoscopic Treatment Of Ventral And Incisional Abdominal Wall Hernias (International Endo Hernia Society (Iehs))-Part A. Surg Endosc 33: 30693139. [crossref]

4. Cruz Alonso Jr. La Endohernioplastia. Detalles Técnicos. Arch Cir Gen Dig [Serie En Internet]. 2007 [Citado 10 De Diciembre De 2010].

5. Carbonell Tatay F (2001) Hernia Inguinocrural. Valencia: Ethicon, 141-142.

6. Deloach Lj, Higgins Ms, Caplan Ab, Stiff Jl (1998) The Visual Analog Scale In The Immediate Postoperative Period: Intrasubject Variability And Correlation With A Numeric Scale. Anesth 86:102-106. [crossref]

7. Halligan S, Parker Sg, Plumb Aa, Windsor Ac (2018) Imaging Complex Ventral Hernias, Their Surgical Repair, And Their Complications. Eur Radiol 28: 3560-3569. [crossref]

8. Henriksen Na, Kaufmann R, Simons Mp Et Al (2020) Ehs and Ahs Guidelines For Treatment Of Primary Ventral Hernias In Rare Locations Or Special Circumstances. Bjs Open 4: 342-353. [crossref]

9. León González Oc, López Rodríguez Pr, Danta Fundora Lm, Satorre Rocha Ja, García Castillo E, Ceruto Ortiz La (2019) Inguinal Hernia Repair By Laparascopy. Surg Cas Stud Op Acc J 3: 2.

10. Bórquez Mp, Garrido Ol, Manterola Dc, Peña P, Schlageter C, Orellana J (2003) Estudio De Fibras Colágenas Y Elásticas Del Tejido Conjuntivo De Pacientes Con Y Sin Hernia Inguinal Primaria. Rev Méd Chile 131: 1273-1279.

11. Díaz Martínez J, Ramírez Colin G (2017) Hernioplastia Inguinal Endoscópico Total Extraperitoneal (Tep). Experiencia De Nuestros Primeros 100 Casos En El Hospital De Segundo Nivel. Cir Endos 18: 125-134.

12. Martin Gómez M (2018) Cirugía Laparoscópica De La Hernia Inguinal. Tep. Cir Andal 29: 174-177.

13. Palmisano Em, Martínez Jd, García Mm, González Jd (2018) Maniobras Claves Y Trucos En Tep. Rev Hispanoamerican Hernia 6: 86-90.

14. Hernia Surge Group (2018) International Guidelines For Groin Hernia Management. Hernia 22: 1-165. [crossref]

15. Liu J, Zhu Y, Shen Y, Liu S, Wang M, Zhao X (2017) The Feasibility Of Laparoscopic Management Of Incarcerated Obturator Hernia. Surg Endosc 31: 656-660. [crossref]

16. Morera Pérez M, Roque González R, González León T, Sánchez Piñero Ro, Olivé González Jb (2019) Cirugía Abdominal En El Adulto Mayor. Rev Cubana Cir 58.

\section{Citation:}

León González OC, López Rodríguez PR, Ceruto Ortiz LA, Satorre Rocha JA, Castillo EG, et al. (2021) Inguinal Hernias Repair by Laparascopy (TEP). Internal Med Res Open J Volume 6(5): 1-3. 